ISSN: $1130-3743$

\title{
LOS SENTIMIENTOS EN LA EDUCACIÓN MORAL
}

\author{
Feelings in moral education
}

\section{Les sentiments dans l'éducation morale}

\author{
Juan Escámez SÁnCHez* y Pedro Ortega Ruiz**
}

${ }^{*}$ Universidad de Valencia. Facultad de Filosofía y Ciencias de la Educación. Departamento de Teoria de la Educación. Avda. Blasco Ibánez, 30. 46010 Valencia. Correo-m: juan.escamez@uv.es

** Universidad de Murcia. Departamento de Teoría e Historia de la Educación. Campus Universitario de Espinardo. Murcia. Correo-e: portega@um.es

Fecha de recepción: enero de 2006

Fecha de aceptación definitiva: abril de 2006

BIBLID [(1130-3743) 18, 2006, 109-134]

RESUMEN

El artículo indaga, en primer lugar, en qué modo los sentimientos forman parte de la dimensión moral de la persona. Se analizan dos problemas complejos y polémicos en la historia del pensamiento: qué son los sentimientos y sus relaciones con la razón en el comportamiento moral de las personas. Como segunda parte, el artículo trata las cuestiones siguientes: la educación de los sentimientos en las tradiciones de las teorías morales; la educabilidad de los sentimientos; la caracterización de algunos sentimientos como morales; la educación de los sentimientos morales de la responsabilidad, la compasión, la justicia como ingrediente de la felicidad, la solidaridad y el amor.

Palabras clave: educación moral, educación de los sentimientos, sentimientos morales. 


\section{SUMMARY}

This article investigates, on the one hand, in what way the feelings are part of the moral dimension of the individual. Tow complex and controversial problems in the history of thought are analized: what are feelings and their relationships with the reason in people's moral behaviour. On the other hand, the article is about the following questions: the education of feelings in moral theory traditions; the educability of feelings; the characterization of some feelings as moral; the teaching of moral feelings of responsibility, compassion, justice as a part of happiness, solidarity and love.

Key words: moral education, education of feelings, moral feelings.

\section{SOMMAIRE}

L'article considère, en premier lieu, la manière comme les sentiments font partie de la dimension morale de la personne. On analyse deux problèmes complexes et polémiques dans l'histoire de la pensée: quels sont les sentiments et leurs rapports avec la raison dans le comportament moral des personnes. Dans une deuxième partie, l'article considère les questions suivantes: l'éducation des sentiments dans les traditions des théories morales; l'éducabilité des sentiments moraux; la caractérisation de quelques sentiments comme moraux; l'éducation des sentiments moraux de la responsabilité, la compassion, la justice comme ingrédient du bonheur, de la solidarité et de l'amour.

Mots clef: éducation morale, éducation des sentiments, sentiments moraux.

\section{INTRODUCCIÓN}

El punto de vista desde el que se trata el presente tema es pedagógico y en él se abordan dos cuestiones principales. La primera, se pregunta el modo como los sentimientos forman parte de la dimensión moral de la persona. La segunda cuestión se refiere a la importancia que hay que conceder a la educación de los sentimientos morales para la formación de personas moralmente educadas; a la vez que se proporcionan algunas orientaciones pedagógicas para la educación de los sentimientos morales de los estudiantes.

La primera cuestión, el modo como los sentimientos forman parte de la dimensión moral de la persona, nos enfrenta a dos problemas complejos y polémicos en la historia del pensamiento filosófico (y también de las ciencias sociales y del comportamiento). El primero, qué sean los sentimientos. El segundo de los problemas está referido a si la realidad o realidades psicológicas denominadas con los términos pasión o emoción o sentimiento son elementos integrantes del comportamiento moral de las personas u obstáculos para el mismo; también se ha formulado este problema de otras diferentes maneras: ela pasión o la emoción o el sentimiento y la razón son enemigos o colaboradores en el comportamiento moral?, ¿el ámbito 
de las pasiones o emociones o sentimientos es ajeno o complementario del ámbito de la razón para el comportamiento moral?

La segunda cuestión, la función de la educación de los sentimientos morales, nos enfrenta a problemas de difícil respuesta y que han tenido un amplio tratamiento en la historia del pensamiento filosófico y en la historia de la literatura a partir del siglo XVIII, especialmente de la novela. El primero de esos problemas es si los sentimientos son educables o, por el contrario, están a un nivel en el que la educación poco o nada puede hacer para incidir en la transformación de los mismos; unido a ese problema, nos encontramos con la cuestión de si la acción educativa puede generar sentimientos morales en donde no los hay o transformar los sentimientos inmorales de las personas en sentimientos morales. Quizás la cuestión más central para la práctica educativa, aunque no la más compleja, consista en aportar razones que justifiquen la conveniencia o necesidad de educar los sentimientos morales para que se pueda prever que las personas, a las cuales se les ha prestado una adecuada educación moral, se comporten moralmente en sus vidas ordinarias y también en circunstancias difíciles cuando el comportamiento moral puede acarrear perjuicios a quien lo practica. Por todos es sabido que la educación de los sentimientos está olvidada en nuestras prácticas escolares y, por otro lado, hay argumentos importantes, extraídos de la reflexión de grandes pensadores sobre los males de nuestro tiempo, que justifican la necesidad de educar los sentimientos morales para combatir las situaciones injustas o inmorales que se han producido y se producen en nuestras sociedades civilizadas, y en las relaciones de unas sociedades con otras y de unos ciudadanos con otros.

Así mismo, hacemos algunas reflexiones pedagógicas para la educación de los sentimientos morales; entre ellos, debido a su importancia, atendemos a la responsabilidad, la compasión, la justicia como ingredientes de la felicidad, la solidaridad y el amor. También convendría prestar atención al peso que en el currículum escolar tenga que concederse a las disciplinas artísticas y humanísticas, a la realización o no de programas específicos para el desarrollo de tales sentimientos y a la formación del profesorado en las técnicas más adecuadas; estas últimas cuestiones desbordan los objetivos que nos hemos propuesto en el presente trabajo.

Ciertamente, los filósofos morales, desde Platón a Wittgenstein ${ }^{1}$, se han planteado si la virtud se puede enseñar, si la ética es una ciencia y si es posible conducir a los

1. Platón y Wittgenstein, representantes eminentes del pensamiento griego y contemporáneo, son considerados maestros en la formulación de esos problemas. Platón dedica el diálogo El Menón al problema de si la virtud puede ser enseñada. No es el momento de analizar toda la cadena de argumentos que conduce a Sócrates y a Menón a la conclusión de que la virtud no puede ser enseñada. Por su parte, WitTGenstein dicta en 1930 una célebre "Conferencia sobre ética" (publicada por primera vez en The Philosophical Review, vol. LXXIV, $\mathrm{n}^{\circ}{ }^{\circ}$, enero de 1965) dirigida a mostrar que la ética constituye un intento de sobrepasar los límites del lenguaje, lo que puede ser dicho con sentido por el lenguaje. El gran filósofo analítico piensa que la ética es algo respetabilísimo en cuanto manifestación de una tendencia profunda del ser humano; sin embargo, no puede ser una ciencia puesto que no aumenta nuestros conocimientos en sentido alguno. 
hombres y a las mujeres al bien. Así mismo, se han buscado distintos fundamentos de las teorías morales y se han enfrentado entre sí los defensores de unas y otras teorías tratando de encontrar los puntos débiles de las teorías rivales. Sin embargo, el papel que desempeñan los sentimientos morales y cómo educarlos apenas ha merecido la atención de los éticos y pedagogos, a pesar de la indudable importancia que tienen para los individuos y las comunidades sociales. La reducción que aparece, una y otra vez, en la sociología del conocimiento se debe al error de tratar el ámbito de las teorías morales como distinto de los intereses y necesidades individuales y de las formas de organización social.

El caso concreto que nos ocupa, los sentimientos y la moral, ha sido uno de los ejes centrales de las discusiones entre teorías morales: «El puesto de la razón en ética y su contraposición con el papel no menos relevante y decisivo de las pasiones, emociones, deseos e intereses humanos, es el núcleo subterráneo, la raíz profunda, de la que surgen todos los restantes debates y polémicas” (Guisán, 1986, 13). La dificultad del asunto que nos ocupa aconseja no entrar en teorías ni metateorías morales y centrarnos sólo en aquellas cuestiones que la perspectiva pedagógica nos requiere y a las que hemos aludido.

\section{LOS SENTIMIENTOS Y LA MORALIDAD DE LAS PERSONAS}

La palabra sentimiento, como concepto técnico en filosofía, no se usa hasta el siglo XVIII. Antes, siguiendo a los griegos, especialmente a los estoicos cuando se habla de moral, se usa el término pasión. Según Julián Marías (1992), en el siglo XVII, Descartes escribe Les Passions de l'âme, que considera como estados del alma, pero con una causa en el cuerpo; las pasiones incitan y disponen al alma a querer las cosas y tienen su preparación en el cuerpo. Las pasiones principales para Descartes son: la admiración (que comprende la estimación y el desprecio, la generosidad y el orgullo, la humildad y la bajeza, la veneración o el desdén y el asombro), el amor y el odio (que incitan a unirse o separarse de lo que parece conveniente o perjudicial), el deseo, la alegría y la tristeza; las demás pasiones las considera composiciones o derivaciones de las anteriores. En la obra citada, llama la atención que el racionalista Descartes reconozca que de las pasiones depende todo el bien y el mal de esta vida, y reserva a la cordura (o sagesse) la habilidad de dirigirlas o gobernarlas. La influencia cartesiana se deja notar en el pensamiento moral continental de la Europa del siglo XVII, como se puede apreciar en el Discours sur les passions de l'amour, atribuido a Pascal, o en el Breve Tratado y en la Ethica de Spinoza, entre otros. Así pues, desde los griegos hasta el siglo XVII, las pasiones son conceptuadas como modalidades del deseo o apetito; a tales modalidades del deseo o apetito se les denominará, cada vez más, con el término "sentimientos" en la Europa continental a partir del siglo XVIII ${ }^{2}$ (Seoane, 2004).

2. En la tradición empirista inglesa, también durante el siglo XVIII, las pasiones y su análisis tienen una importancia fundamental en las concepciones morales. Para Hume, Tratado de la Naturaleza 
La primera cuestión que nos planteamos es ontológica ${ }^{3}$ : ¿Qué son los sentimientos? Los sentimientos son: a) estados del sujeto, b) en cuanto afectado por las realidades con las que vive, c) que producen un impulso de aproximación hacia lo que el sujeto percibe como bueno y de huida de lo que percibe como perjudicial.

Así, los sentimientos son estados del sujeto, es decir, modos de sentirse un sujeto, a diferencia de la inteligencia que pretende conocer las cosas como son, o de la voluntad que quiere decidir sobre la bondad de las cosas. Los sentimientos son modos como un sujeto se siente, característicos de él como todas las demás cualidades que tiene como suyas, en cuanto pertenecen a su intimidad, como el color de la cara o su convicción política o religiosa.

Los sentimientos, como modos de sentirse, son acomodaciones vitales del sujeto a sus percepciones de la realidad: "La esencia formal del sentimiento es ser atemperamiento ${ }^{4}$ a la realidad" (Zubiri, 1992, 335). Los sentimientos no son solamente actos del sujeto, sino que en ellos está envuelta una realidad que, a su modo, le está presente. Sin esto no serían sentimientos. Los sentimientos son ciertamente actos del sujeto, pero no son ni más ni menos subjetivos que las intelecciones o las voliciones. El sentimiento es una acomodación a la realidad, a una realidad que es ciertamente del sentimiento y está presente a él. La realidad ${ }^{5}$ no solamente es de la inteligencia como aprehendida en ella, ni sólo es realidad como apetecida por la voluntad sino que es también realidad del sentimiento. ¿Qué se pretende decir con la expresión "es también realidad del sentimiento"? ¿En qué consiste que la realidad sea también del sentimiento?

Para X. Zubiri (1986), el hombre tiene una estructura unitaria, que llamamos su modo de habérselas con las cosas, el modo de habérselas con ellas como realidades. Pues bien, el hombre se enfrenta con las cosas como realidades o, dicho de otra forma, las cosas se hacen presentes al sujeto no como meros estímulos sino como realidades estimulantes. Toda presencia o actualización ante el sujeto es de una realidad. Estamos habituados a ver en la realidad el correlato de una intelección o de una volición; tendríamos que habituarnos a introducir en el pensamiento la idea de que también la realidad es percibida como correlato de un sentimiento.

Los sentimientos son experiencias conscientes en las que el sujeto se encuentra implicado, interesado, complicado. Pero son experiencias de realidad y en eso consiste su objetividad. La lengua castellana expresa sabiamente esta implicación afectiva de sentimientos y realidad. Por un lado, conjugando los sentimientos en voz media: me siento alegre, triste, deprimido, feliz, enamorado. En cada una de

Humana, la moral debe ser entendida, explicada y justificada por referencia al lugar de las pasiones y deseos en la vida humana. Por ello, hablamos de la Europa continental.

3. No carece de interés preguntarnos, de vez en cuando, por la naturaleza de las cosas.

4. Atemperar significa acomodar una cosa a otra (Diccionario de la lengua española. Real Academia Española, 1984).

5. Consideramos que la obra de X. ZuBiri en la que da una visión más acabada de lo que entiende por "realidad" es: (1980) Inteligencia sentiente. Madrid, Alianza Editorial-Sociedad de Estudios y Publicaciones. 
esas frases, hay una presencia del sujeto; es él quien siente, pero también es una parte de lo sentido; se siente a sí mismo triste, alegre, deprimido, enamorado, feliz o desgraciado. Por otro lado, ese sentirse hace referencia a algo: "Los objetos forman aleación con el yo, se entraman con él. Le afectan. Ésta es la experiencia inaugural de nuestro trato afectivo con la realidad. El sujeto está en el sentimiento. Vive sentimentalmente, alumbra el mundo con su luz sentimental" (Marina, 1996, 77).

$Y$ por eso es por lo que, en última instancia, los sentimientos no son meramente subjetivos. Todos los sentimientos nos presentan facetas de la realidad, no solamente estados míos. Se ha dicho y se ha comentado que el amor ve aspectos que no ve la pura inteligencia. Pero esto no es exclusivo del amor; es propio de todo sentimiento. Todo sentimiento es vidente de la faceta de la realidad que nos presenta.

Es necesario insistir en dos aspectos de la antropología filosófica moderna que no suelen comprenderse bien. El primer aspecto, que la persona es una realidad unitaria, o un sistema unitario, que se relaciona con un medio percibido como un conjunto de realidades con las que interactúa para solucionar los problemas de su vivir; todo en la persona (lo biológico, lo emocional y lo cognitivo) conforma esa unidad profunda de ser elementos de un mismo sistema. El segundo aspecto, que la persona también es un sistema complejo en sus relaciones con el medio al que trata de conocer (la inteligencia), al que siente como facilitador o perturbador de la función radical de vivir (los sentimientos) y por eso reacciona acercándose o huyendo, y al que usa y transforma para solucionar los problemas de su vida (las decisiones y las acciones).

La relación de los elementos que conforman el sistema humano es profunda. En la danza entre el sentir y el pensar, los sentimientos guían nuestras decisiones instante tras instante, trabajando mano a mano con la mente racional y capacitando $\mathrm{o}$ incapacitando al pensamiento mismo. $\mathrm{Y}$ del mismo modo, el pensamiento desempeña un papel fundamental en nuestros sentimientos, exceptuando aquellos momentos en los que los sentimientos se desbordan y asumen por completo el protagonismo de la situación (Goleman, 1996).

La segunda cuestión compleja a la que nos enfrentamos es la siguiente: ¿Son los sentimientos elementos integrantes de la moralidad de las personas? La consideración de la razón y los sentimientos como integrantes de la moralidad tiene una amplia tradición en la historia del pensamiento. En la ética aristotélica, las virtudes son disposiciones no sólo para actuar de maneras particulares, sino para sentir de maneras particulares. Actuar virtuosamente no es, como Kant pensaría más tarde, actuar contra la inclinación; es actuar desde una inclinación formada por el cultivo de las virtudes. En dicha tradición aristotélica, la educación moral es concebida como una educación de los sentimientos (MacIntyre, 1987, 1994). La importancia de los sentimientos como ingredientes de la vida moral aparece en la amplitud de estudio que se concede a los mismos (felicidad, placer, amistad) en toda la ética nicomáquea ${ }^{6}$. Como una muestra de tal afirmación, en el capítulo I del libro X de la Ética a Nicómaco, Aristóteles dice:

6. Aristóteles, en la Ética a Eudemo y en la Ética a Nicómaco, así como en el Tratado sobre el Alma, da por primera vez un cuadro sistemático de las pasiones, que eran los antecedentes de los 
Por esta razón se forma la educación de la juventud, valiéndonos del placer y del dolor, como quien se sirve de un poderoso timón, ya que lo más esencial para la moralidad del corazón consiste en amar lo que debe amarse y aborrecer lo que se debe aborrecer. Estas influencias persisten durante toda la vida, y tienen un gran peso y una gran importancia para la virtud y para la felicidad, puesto que el hombre busca siempre las cosas que le agradan y huye de las cosas penosas.

Aristóteles ha de ser visto como un heredero de la paideia griega, que consideraba el esfuerzo por la areté o virtud como producto del amor propio así como de una alta valoración del anhelo del honor. En la tradición homérica, quien se estima a sí mismo debe ser infatigable en la defensa de sus amigos, sacrificarse en honor de su patria, abandonar gustoso dinero, bienes y honores para apropiarse de la belleza. En el amor a sí mismo se revela lo más peculiar y original del sentimiento griego de la vida y el íntimo motivo de la areté o virtud (Jaeger, 1962). Igualmente, Aristóteles es el heredero de la tradición expuesta por su maestro Platón en El Filebo donde, más allá de ser un tratado sobre la naturaleza del placer, defiende la bondad de la vida como una mezcla de sabiduría y placer. Los sentimientos, por lo tanto, son fundamentales en la concepción moral de los griegos.

La presencia de la razón y los sentimientos, como elementos integrantes de la moral, se plantea problemática sólo a partir de mediado el siglo XVII con el proyecto ilustrado de proveer una justificación racional independiente para la moral. Desde 1630 a 1850, la moral se convirtió en el nombre de esa peculiar esfera donde una reglas de conducta que no son teológicas, ni legales ni estéticas alcanzan un espacio propio, y la distinción de lo moral de lo teológico, lo legal y lo estético se convirtió en doctrina admitida. El proyecto de justificación racional independiente para la moral llegó a ser una cuestión central para la cultura europea.

Creemos que la buena comprensión de ese cambio de perspectiva de la moral es de sumo interés para explicarnos el divorcio existente entre sentimientos y razón, a partir de entonces ${ }^{7}$. Ciertamente, son las preocupaciones epistemológicas,

sentimientos. Estructuró las pasiones de acuerdo a dos apetitos: el concupiscible y el irascible. Las pasiones concupiscibles son: el amor, que es la inclinación hacia el bien conocido; el odio, que es la aversión al mal conocido; el deseo, que es el movimiento hacia el bien aprehendido como ausente y futuro; la fuga, que es el movimiento para apartarse del mal aprehendido como ausente y futuro; el gozo, que es el deleite o descanso en el bien poseído; y la tristeza, que es el desaliento por el mal presente. Las pasiones irascibles son: la esperanza, que es el movimiento hacia el bien arduo y presente, pero que puede alcanzarse; la desesperación, que es el alejamiento del bien arduo e imposible de alcanzar; la audacia, que es el movimiento frente al mal arduo, inminente y superable; el temor, que es el abatimiento por el mal arduo, inminente e inevitable; y la ira, que es el movimiento hacia la venganza, esto es, a dañar la causa del mal. Sobre este asunto, Bernal, A. (1998) Educación del carácter/educación moral. Propuestas educativas de Aristóteles y Rousseau. Pamplona, Eunsa (especialmente pp. 59-64).

7. Aunque los expertos hoy distinguen entre moral y ética, siendo esta última objeto de debate filosófico (la ética) en contraste con la moral que se nos presenta como la exigencia de responder de nuestros actos, de los que de un modo u otro tenemos que hacernos cargo, una y otra vez se confunden sus significados por quienes hablamos y escribimos de estos asuntos. 
de justificación o legitimación del conocimiento moral, las que producen la ruptura de sentimientos y razón en la filosofía de la Ilustración. Es en la filosofía moral o ética donde se produce el desgarramiento de la razón y de los sentimientos, no en el comportamiento moral de las personas que no puede ser explicado sin el concurso de ambos elementos.

Nos encontramos con dos planos diferentes del discurso moral que frecuentemente se confunden. En el primero de ellos, las tradiciones morales antes de la Ilustración, se hacía filosofía moral como teorías morales para guiar la vida de los hombres y las mujeres en las circunstancias en las que les toca vivir; en otras palabras, se hacen teorías prácticas. En el capítulo II del libro II de la Ética a Nicómaco, dice Aristóteles:

No debe perderse de vista que el presente tratado no es una pura teoría, como pueden serlo otros muchos. No nos consagramos a estas indagaciones para saber qué es la virtud, sino para aprender a hacernos virtuosos y buenos; porque de otra manera este estudio sería completamente inútil. Es, por tanto, necesario que consideremos todo lo que se refiere a las acciones para aprender a realizarlas, porque ellas son las que deciden soberanamente de nuestro carácter, y de ellas depende la adquisición de nuestras cualidades.

En el segundo de esos planos, las tradiciones morales que se inician en la Ilustración, se hace lo que hoy entendemos como metateoría de la moral: una indagación o investigación sobre el fundamento de la moral. Lo que intentan los ilustrados, y han seguido intentado la mayoría de las tradiciones en la filosofía moral posterior a ellos, es la determinación de las condiciones que tiene que cumplir la razón para alcanzar un fundamento satisfactorio del hecho moral o establecer una explicación satisfactoria del origen del fenómeno moral. No les preocupa, como propósito primero, encontrar orientaciones que guíen las acciones de las personas para ser virtuosas y felices (tal como hasta entonces habían pretendido las tradiciones de la filosofía moral desde los griegos).

La preocupación ilustrada lleva a Hume, en el Tratado de la Naturaleza Humana, a la conclusión de que la moral debe ser entendida, explicada y justificada por referencia al lugar de las pasiones y deseos en la vida humana; en su postulado inicial de que la moral o es obra de la razón o es obra de las pasiones, su investigación le conduce a que no puede ser obra de la razón y, por ello, se ve abocado a la conclusión de que la moral es obra de las pasiones. La razón fundamental se debe a la concepción de la tradición empirista inglesa sobre que las pasiones son producidas por cierto tipo de impresiones y son las que generan las acciones humanas.

Por su parte, Kant, en la Crítica de la Razón Pura, establece las condiciones del conocimiento científico: sólo podemos conocer fenómenos, aquello de lo que tenemos experiencia. Así fundamenta la ciencia frente al relativismo escéptico; los datos sólo pueden llegar a nuestra conciencia cognoscente a través de intuiciones empíricas. Pero acontece que la conciencia humana no es sólo conciencia cognoscente 
sino también conciencia moral, a la que dedica la Crítica de la Razón Práctica. En ella, defiende que esa conciencia moral nos muestra un hecho absolutamente inexplicable por todos los datos del mundo sensible; este hecho es la ley moral. Ese hecho de la ley moral no depende de la contingencia de su presentación a la sensibilidad; el hecho moral se da "a priori". Es un hecho que brota de la razón humana. El hecho de la conciencia de la ley moral es un hecho de la razón, libre de toda necesidad de presencia en la experiencia.

Nos encontramos así con dos concepciones de la moral: la moral kantiana que es una moral a priori o de la razón, con unos principios universales que obligan a cualquier ser humano que pretenda comportarse racionalmente, sean cualesquiera sus preferencias, deseos y situación; tal moral racional postulará principios que deben ser mantenidos por toda persona, independientemente de circunstancias y condiciones. Y, por otro lado, la tradición que arranca de Hume que fundamenta la moral en las pasiones, que motivan a los humanos a perseguir ciertos tipos muy generales de bienes, una y otra vez a lo largo de su vida, como una inclinación de su naturaleza. Hume sostiene que la razón no nos puede motivar. Y las pasiones, que sí motivan, no son en sí mismas ni razonables ni no-razonables; por lo que no son objeto de verdad o falsedad. Ni pueden tener ni dejar de tener garantía racional, ni pueden ser congruentes ni incongruentes con los requerimientos de la razón.

El divorcio entre razón y sentimientos está servido y así se ha mantenido en los debates suscitados en la filosofía moral desde la Ilustración y, en cierto modo, la polémica pervive en los enfrentamientos teóricos actuales de liberales y comunitaristas. Los temas epistemológicos se han constituido como los temas centrales de la filosofía, también de la filosofía moral, a partir de la Modernidad. Sin embargo, desde la segunda mitad del siglo XX, se vienen produciendo nuevos planteamientos teóricos, que buscan caminos de reconstrucción del desgarramiento producido entre sentimientos y razón en la ética de la Ilustración, y nuevas miradas de intelectuales que tratan de comprender los comportamientos de los humanos, desde la perspectiva moral, en los acontecimientos graves que han ocurrido, especialmente el Holocausto, y están ocurriendo en el mundo.

En cuanto a la reconstrucción del desgarramiento producido entre sentimientos y razón en la ética moderna y contemporánea, Esperanza Guisán muestra los esfuerzos que han venido haciéndose en su excelente estudio, Razón y pasión en ética. Los dilemas de la ética contemporánea (1986). La tesis central de su trabajo consiste en apostar por la necesidad de que la filosofía moral contemporánea reconozca la unión inseparable de razón y sentimientos, como momentos distintos, aunque continuos, no escindidos, sino interconectados, entre las capacidades reflexivas del hombre y sus capacidades de sentir, padecer, compadecer y sentir con los otros. Para ello, analiza las vinculaciones entre ética y naturaleza humana, y considera al sentimiento como fundamento y determinante de la moralidad. En concreto, busca las vinculaciones entre justicia y felicidad, ideales que en muchos 
autores del pensamiento moderno y contemporáneo han aparecido disociados, contrapuestos e irreconciliables.

E. Guisán, después de analizar las propuestas sobre las relaciones de los sentimientos y la razón en la moral, en autores tan importantes como Hare (1952, 1981) y Brandt (1979, 1982), formula sus propias propuestas así: 1) El lenguaje moral no es racional, si por racional se entiende su desconexión de lo emocional, haciéndolo dependiente de verdades universales o imperativos categóricos que no tienen en cuenta las inclinaciones humanas; 2) El lenguaje moral no es emotivo, si por emotivo se entiende el recurso a la pura subjetividad, a saber, lo que cada uno desea que sea el comportamiento de los demás teniendo en cuenta sus solos intereses, gustos o preferencias; 3) Los enunciados éticos son racionales únicamente en tanto que la racionalidad emana de la intersubjetividad y se asienta en la facticidad de las necesidades generadas en la convivencia humana; 4) Los enunciados éticos son emotivos únicamente en la medida en que se visten de racionalidad.

No tan preocupados por las cuestiones epistemológicas, por la posibilidad de la ética como ciencia o por las singularidades que presentan los enunciados éticos, sino enfrentados al candente problema de lo que se debe hacer ante los acontecimientos graves de la vida, adoptando ante ellos una perspectiva moral como dimensión humana inevitable, es decir, haciendo teorías morales más que metateorías morales, Horkheimer, Adorno y Levinas aportan propuestas muy sugerentes que muestran la inadecuada separación de los sentimientos y la razón, tal como se ha producido desde la ética de la Ilustración. Presentamos una síntesis de las ideas de esos autores bajo cuatro apartados: 1) la moral es resistencia al mal; 2) el impulso moral surge de la experiencia de sufrimiento de las víctimas y 3) del encuentro con el otro; 4) el impulso moral se traduce en compasión y compromiso político para la transformación de las estructuras sociales injustas.

La moral es resistencia al mal. "No cabe la vida justa en la vida falsa"; con estas palabras denuncia Adorno (2004, 44) la hipocresía de una sociedad burguesa que pretende alcanzar un nivel de vida humana, moralmente digna, en complicidad con estructuras de dominación y sometimiento, que ahogan la libertad y la posibilidad misma de vivir en justicia. La condición de posibilidad de la vida moral está vinculada a la crítica de la contradicción existente entre principios o máximas morales y vejación y explotación de seres humanos. Crítica que pone en primer plano la interpretación individualista de la conducta moral para situarla dentro de una comunidad social e histórica. La postura crítica de Adorno no pretende fundamentar ninguna moral, "Sino más bien sacar a la luz su compleja significación tanto en relación con los intereses y deseos individuales, como respecto a las exigencias sociales" (Zamora, 2004, 258).

El concepto de moral en Horkheimer y Adorno no es separable de la situación histórica que les tocó vivir. La obra filosófica de estos autores refleja la experiencia de desgarro que supuso el Holocausto judío y la profunda decepción en el proyecto ilustrado al que acusan de haber contribuido a una dialéctica de progreso y barbarie. La experiencia de que uno se ha salvado mientras otros han perecido 
hace brotar en el sujeto el sentimiento de un privilegio, de ser segregado de otros, a la vez que la amarga experiencia de no tener personas a quienes agradecer el poder seguir viviendo (Levi, 1989; Steinberg, 2004). La pregunta: ¿por qué uno vive y otros no? es simplemente insoportable.

La resistencia a lo que "no debe ser" no es sólo al sufrimiento histórico de las víctimas, sino a toda forma de dominación y sometimiento, a una forma de pensar que lo reduce todo a la identidad, a la inmanencia, a uno mismo, destruyendo con ello el sentido de la diferencia, de lo otro. Resistencia frente a una sociedad ilustrada que ha olvidado el compromiso de emancipación del hombre y ha hecho de la Ilustración un sistema totalitario como ningún otro sistema (Horkheimer y Adorno, 1994).

Desvelar el mal histórico, sacar a la luz los mecanismos de dominación sobre los más débiles es una función irrenunciable de la moral, es su razón de ser; resistir la propaganda de ocultación que impide el conocimiento de los sufrimientos que provoca es una tarea inaplazable. Pero Horkheimer y Adorno no hacen sólo una crítica al sistema que ha hecho posible vivir en la indignidad o falsedad. Se rebelan contra los ultrajes perpetrados a los hombres y mujeres de su tiempo, contra la inhumanidad existente. Esa resistencia no es frente a un mal invisible, sino contra la deportación y el crimen, el aniquilamiento organizado de los seres humanos. Es esta experiencia histórica del sufrimiento de seres humanos la que constituye, al margen de otro fundamento trascendente, un mandato de resistir al mal. No es posible derivar una moral desde el bien ideal, colgarla en el cielo de lo universal y esperar del individuo que camine mirando hacia arriba. La experiencia del mal exige a la moral descender al individuo concreto, pensarla desde sus experiencias cotidianas o excepcionales, desde su dolor (Tafalla, 2003b).

Para Horkheimer y Adorno, el progresivo proceso de dominio del hombre sobre la naturaleza ha acabado por ahogar la esperanza de su emancipación (1994). Si el objetivo del proceso de racionalización en la Modernidad era la autoconservación del individuo, la lógica del dominio a lo que realmente ha llevado ha sido a la imposición del sistema, como lo prueba la historia constante de sufrimiento, de sacrificio de sus excluidos: "Se inculca al individuo, desde sus primeros pasos, la idea de que sólo existe un camino para saber manejárselas en este mundo, el de abandonar la esperanza de una máxima autorrealización" (Horkheimer, 2002, 153). Adaptación, sumisión, mimetismo serán las condiciones básicas para la supervivencia del individuo.

No es la negación del individuo lo que Horkheimer defiende o su absorción en una conciencia colectiva, sino la necesidad de un sujeto capaz de resistir a la injusticia y a la dominación, que haga suya la causa histórica de los otros desde la solidaridad. Pero esta posibilidad de emancipación que rompe la lógica del dominio sólo puede venir si se gana la intersubjetividad y se establece un nuevo concepto de sujeto-individuo desde la lógica de la debilidad, desde el derecho de los excluidos. Éstos son alos verdaderos individuos de nuestro tiempo... que han atravesado infiernos de sufrimiento y de degradación por su resistencia al 
sometimiento y a la opresión, no las hinchadas personalidades de la cultura de masas, los dignatarios convencionales" (ibídem, 2002, 168).

El impulso moral surge de la experiencia del sufrimiento de las víctimas. La rebelión contra el mal y el deseo de felicidad no nacen del impulso del conocimiento del bien y del mal. No son los principios y máximas morales los que nos empujan a una conducta moral. Más bien es la aspiración a que la experiencia del dolor y de la miseria sufrida por la inmensa mayoría de los hombres no tenga la última palabra. Es esta experiencia histórica, y no el conocimiento del bien o ideal de una humanidad feliz, la que nos mueve o impulsa a una vida moral, es decir, responsable. Ni el conocimiento del bien, ni la "buena voluntad" nos impulsan a una conducta moral, sino la experiencia del mal, del sufrimiento del otro; el rostro y la vulnerabilidad del "huérfano y de la viuda" demandan una respuesta moral, es decir, responsable. La moral en Horkheimer y Adorno no deriva de la razón, como en la moral kantiana y en sus versiones actuales. No es un hecho de la razón pura que se impone como un imperativo categórico, absoluto. Por el contrario, el impulso moral brota de la experiencia de sufrimiento de los seres humanos excluidos del derecho a la felicidad.

La moral hunde sus raíces en el mismo suelo, en la misma historia de sufrimiento de la que brotaron los anhelos de felicidad, la exigencia de justicia plena, consumada, en "el anhelo de que todo el horror que sucede en este mundo, el destino inmerecido y terrible de muchos hombres no sea algo definitivo" (Horkheimer, 2000,210 ), el anhelo de que no quede todo en la injusticia que atraviesa este mundo. Se trata de dar respuesta a la esperanza de los otros, de los excluidos de la felicidad en las condiciones históricas presentes.

Adorno (1975, 282-283) denuncia todo intento de racionalizar el dolor y el sufrimiento para reducirlo a frases como: "No torturarás, no montarás campos de concentración, a pesar de que todo eso siga ocurriendo en África y en Asia bajo el silencio de la humanidad civilizadora, siempre inhumana contra los que desvergonzadamente estigmatiza como incivilizados". La angustia por el sufrimiento ajeno es la mecha que enciende la praxis moral, no la razón autolegisladora. Y la respuesta moral ante la miseria ajena no admite demora ni fundamentación, sino poner fin a una situación de injusticia. La superación práctica del sufrimiento no tolera ningún aplazamiento, ni perderse en disquisiciones sobre el conocimiento del bien. Éste ya lo conocemos a través del conocimiento empírico del mal. Es la necesidad evidente de la eliminación del sufrimiento la que justifica toda moral. Sólo esta necesidad es la que confiere fuerza al imperativo moral.

¿Qué hay en la base de la moral como la entienden Horkheimer y Adorno? ¿Es una pura reacción emotiva carente de razón? No se trata de una reacción emotiva ciega a la razón. No hay una reducción de la moral a un puro sentimiento individual desprovisto de racionalidad, si bien en el origen de esta moral está el sentimiento, el "pathos", el anhelo de justicia que ponga fin al sufrimiento de los excluidos de la felicidad a la que tienen derecho; está la urgencia de solidaridad con los miserables. En esta moral no es la razón la que nos inclina a obrar según 
el deber, pero tampoco es un sentimiento irracional. Es una afección (sentirse afectado, sufrir) en la conciencia por el reconocimiento de los otros en sus circunstancias concretas.

La moral no se funda sólo en la razón, ni tampoco en la indignación que nos produce el sufrimiento de los inocentes, "en todo caso, en una dialéctica entre ambos que no suprima la tensión, que no siente un primer principio ni anticipe una reconciliación a expensas de uno de los polos" (Zamora, ibídem, 268). La moral hay que construirla partiendo de experiencias concretas, avanzando por negación a partir de cada vivencia del mal y del dolor. Sólo el aprendizaje y la negación nos permiten esbozar una moral. Más aún, podríamos afirmar que sólo con la acumulación de experiencias puede la moral ir adquiriendo progresivamente un carácter universal que no lo será nunca de manera definitiva. La moral es una historia que comienza con la experiencia y continúa con la experiencia. El mejor de los ejemplos es el desarrollo de los derechos humanos que no es sino un proceso que avanza negando formas de injusticia.

El encuentro con el otro. El impulso moral en Levinas se entiende como una exigencia de responder. La moral es responsabilidad, hacerse cargo del otro, sin preguntar de dónde viene. La presencia del rostro, en su vulnerabilidad, me hace rehén suyo sin necesidad de acudir a argumentos para justificar una respuesta moral: "El rostro se me impone sin que yo pueda permanecer haciendo oídos sordos a su llamada, ni olvidarle; quiero decir, sin que pueda dejar de ser responsable de su miseria" (Levinas, 1993b, 46). El imperativo de responder no va ligado a la reciprocidad o reconocimiento en el otro de la ayuda prestada. El otro lo reclama, y cueste lo que cueste, no se puede pasar indiferente delante de él: «El lazo con el otro no se anuda más que como responsabilidad, y lo de menos es que sea aceptada o rechazada, que se sepa o no cómo asumirla, que se pueda o no hacer algo concreto por el otro... yo soy responsable del otro sin esperar la recíproca, aunque ello me cueste la vida. La recíproca es asunto suyo" (Levinas, 1991, 91-92).

Más aún, Levinas entiende que el sujeto moral se encuentra ante el otro como "habitado desde siempre por la alteridad", como consagrado y expuesto a ella, sin que él haya podido escogerla voluntariamente. Este hallarse el sujeto moral con la tarea asignada de responder del otro, sin que ello sea la consecuencia de una decisión libremente tomada, lo sitúa en el más completo "abandono de sín para estar en las "manos del otro", en una pasividad radical (Levinas, 1993).

La moral en Levinas es "an-árquica", no establece principio alguno universal e incondicionado que guíe el comportamiento humano (moral) ante el otro; no aborda la conducta moral con la idea previa de la dignidad de la naturaleza humana. No empieza la moral por poner en práctica principios morales, sino en dejarse atrapar por el otro, en obedecer a un mandato: la obligación de responder, de hacerse cargo del otro, sin condición ni principio.

Alimentar a los hambrientos, esconder a los perseguidos y hallar recursos para salvarlos, no constituye el término de una reflexión llevada a cabo con total 
independencia de espíritu, aun cuando hubiera sido orientada por el hermoso principio de la dignidad de la naturaleza humana. La tremenda prontitud de los gestos que hay que hacer no da ni el tiempo de examinar los pormenores de la situación, ni el de sopesar las consecuencias que le acarrearán a uno mismo (Chalier, 2002, 27).

Frente al otro sólo cabe (moralmente) el reconocimiento, la obediencia. El otro se me impone sin que nadie me pueda librar de él.

Si la ética de la Ilustración construye la moral desde la irrenunciable autonomía del sujeto, Levinas ve en la heteronomía la única puerta de acceso al ámbito de la moral. Para él, la moral es responsabilidad, responder del otro. Levinas no aspira a fundamentar una ética, sino a pensar cómo la inquietud por la suerte del prójimo surge en el hombre, a menudo a pesar suyo, sin buena voluntad de su parte. Muy al contrario, dice, el sujeto forzado a despertarse a la preocupación moral preferiría casi siempre eludir las exigencias que la misma implica. Nadie se vuelve moral por buena voluntad ni por haber decidido universalizar las máximas de sus acciones, sino por responder a un mandamiento que emana del encuentro del rostro del otro. Pero en Levinas el sentimiento moral (la sensibilidad) no es lo que mueve al sujeto a la acción moral, es más bien una condición "original". La condición de vulnerabilidad es anterior a cualquier sentimiento de amor u odio.

El impulso moral se traduce en compasión y compromiso político para la transformación de las estructuras sociales injustas. Desde Spinoza y Nietzsche, la compasión no ha gozado de estima en el discurso moral. Más bien ha sido vista como una ilusión romántica o como resignación ante la imposibilidad de la justicia; como un mecanismo para enmascarar la injusticia y favorecer su continuidad. Es cierto que la compasión se ha visto envuelta en consideraciones de tipo religioso y se ha traducido, no pocas veces, en obras de beneficencia, sin preguntarse o cuestionar las raíces del mal, del sufrimiento y miseria del otro. Para nosotros, en cambio, la compasión no suple a la justicia, es inseparable de ésta: "Es un encuentro con el hombre desposeído, con "toda" su realidad, a la vez que un compromiso político de ayuda y de liberación que lleva a trabajar por transformar las estructuras injustas que generan sufrimientos y situaciones de dependencia y marginación" (Ortega y Mínguez, 2001, 108).

En la compasión, el compadecido no es el individuo abstracto y sin contexto. Es la persona concreta, herida y ultrajada, pero con exigencias de dignidad. El compadecido reclama una deuda pendiente y el que compadece no hace sino dar lo debido. Es el otro, alguien concreto, quien desde su alteridad reclama el reconocimiento de su dignidad ultrajada. El compasivo sufre con los otros porque no acepta como normal la situación de su sufrimiento; vive del anhelo de una situación social diferente donde no exista la injusticia y el dolor evitable y gratuito. En la compasión late siempre un sentido de justicia (Mardones, 2005).

La moral en Horkheimer es constitutivamente compasiva. El sentimiento de compasión está no sólo en el origen de la moral como impulso, sino que la atraviesa de parte a parte. “Mientras que la moral, pues, tenga una razón de ser, habita 
en ella la compasión. Incluso puede sobrevivirla... (porque) en la naturaleza sigue imperando el sufrimiento y la muerte" (Horkheimer, 1999, 139). Si hoy es el primer sentimiento moral nacido del sufrimiento contra el que se puede combatir, la compasión subsistirá siempre como la virtud nacida del y frente al dolor irremediable (Arteta, 1996). Mientras la historia sea para gran parte de los hombres historia de sufrimiento y exclusión habrá lugar para la compasión.

La compasión es un sentimiento moral por el que nos reconocemos deudores de la situación del otro, de su sufrimiento. Sufrimiento no elegido, ni querido y tampoco inevitable. Pero este otro tiene un rostro, es alguien y su sufrimiento es también concreto, ligado a situaciones históricas que hacen imposible vivir en dignidad. Para Levinas, en un mundo poblado de otros, la respuesta a éstos puede ser de indiferencia, de apoderamiento o de reconocimiento y acogida. Es decir, la indiferencia que les niega el estatuto de realidad, el apoderamiento que busca adueñarse de ellos a cualquier precio y la acogida por alguien que se reconoce en el otro. En estas situaciones, la presentación de los otros se hace a través de la transparencia de un rostro que se me presenta en persona. A este espacio de la presentación Levinas lo llama ética, pues la respuesta moral no es la comprensión, sino la compasión (cum-pati), entendida como cuestión de entrañas, de sufrimiento compartido (Ortega, 2004). La compasión supone una relación intersubjetiva, de reconocimiento del otro y de mi responsabilidad hacia él. Es, por tanto, una relación radical y originariamente moral.

La moral es también política: "La otra forma en la que, hoy en día, la moral encuentra una expresión adecuada, es la política" (Horkheimer, 1999, 139). El sentimiento moral no queda reducido a una relación ideal y privada "yo-tú" en la que sólo intervienen individuos singulares, sacados de su contexto social e histórico. No está desligada de los problemas que acucian a la humanidad, sino que brota de ellos y, por tanto, no está desligada de la realización en la práctica, ni la cuestión de la justicia desligada del derecho a la felicidad.

La concepción de la justicia como felicidad se refiere, precisamente, a la transformación de las estructuras sociales de tal modo que garanticen que cada persona tiene la información y la libertad precisa para formarse su plan de vida y que, asimismo, cuenta con los medios precisos para la satisfacción de sus necesidades básicas de toda índole (Escámez, García y Pérez, 2003).

\section{LA EDUCACIÓN DE LOS SENTIMIENTOS MORALES}

En esta parte tratamos las cuatro cuestiones siguientes: 1) la educación de los sentimientos en las tradiciones de las teorías morales, 2) las razones por las que se pueden educar los sentimientos, 3) la caracterización de algunos sentimientos como morales, 4) la educación de los sentimientos morales de la responsabilidad, de la compasión, de la pasión por la justicia como parte integrante de la felicidad, 
de la solidaridad y del amor para que las personas se comporten moralmente en las complejas y, a veces, difíciles circunstancias de sus vidas.

Como hemos expuesto anteriormente, la paideia griega y la tradición moral aristotélica consideraban la educación de los sentimientos como un elemento central de la educación moral. Así lo reconoce Goleman $(1996,17)$ :

En su Ética a Nicómaco, Aristóteles realiza una indagación filosófica sobre la virtud, el carácter y la felicidad, desafiándonos a gobernar inteligentemente nuestra vida emocional. Nuestras pasiones pueden abocar al fracaso con suma facilidad y, de hecho, así ocurre en multitud de ocasiones; pero cuando se hallan bien adiestradas, nos proporcionan sabiduría y sirven de guía a nuestros pensamientos, valores y supervivencia.

La consideración de la centralidad de los sentimientos para la educación moral se ha mantenido en la actual Teoría de la Educación Moral del Carácter. Sus defensores (Etzioni, 1988; Lickona, 1991; Bernal, 1998) consideran que la educación de los sentimientos es uno de los armazones básicos del carácter. La capacidad de demorar la gratificación, de controlar y de canalizar los impulsos constituye una habilidad emocional fundamental a la que antiguamente se le llamó fuerza de voluntad. Así mismo, la capacidad de armonizar nuestros impulsos e intereses con los intereses de los demás tiene considerables beneficios sociales, puesto que abre el camino para asumir el punto de vista de los demás; y, en consecuencia, claras repercusiones morales, pues conduce al respeto, al altruismo y a la compasión (Hoffman, 2002).

Se trata de vivir lo mejor posible sin perjudicar a los demás y ayudándoles en lo que se pueda; así podemos caracterizar la vida moral en su sentido más elemental. Y eso supone una dosis no despreciable de altruismo moral que incluye los sentimientos de empatía y ayuda mutua. Ver las cosas desde el punto de vista de los demás permite superar las visiones sesgadas y alienta la aceptación de las diferencias, permitiendo vivir en una sociedad basada en el respeto mutuo que propicia la existencia de un discurso público constructivo, que es siempre elemento fundamental de vida democrática.

Además de la Educación Moral del Carácter, el resto de las principales teorías contemporáneas de la educación moral, el Desarrollo del Juicio Moral y la Filosofía para Niños, son coincidentes en que una adecuada educación moral tiene que desarrollar en los estudiantes tanto los conocimientos morales como los sentimientos para que sean verdaderos agentes de acciones morales en las relaciones de unos con otros y con las instituciones sociales (Escámez, 2003); bien es cierto que unas teorías prestan más atención a los aspectos cognitivos y otras a los afectivos, pero ninguna de las actuales teorías de la educación moral excluye el desarrollo de los sentimientos y los conocimientos morales.

¿Por qué todas las teorías morales han considerado necesaria la educación de los sentimientos? ¿Es posible tal educación? Empecemos por la segunda cuestión. Hemos dicho anteriormente que los sentimientos cumplen una función de 
adaptación o acomodación vital del sujeto a su percepción de la realidad; los sentimientos son impulsos o movimientos de acercamiento o huida ante la percepción de las realidades, con las que nos ha tocado vivir, como gratificantes o perjudiciales. Ciertamente son predisposiciones biológicas que, en las personas, son modeladas por la cultura y por la experiencia biográfica de cada una de ellas. Algunas veces, por la intensidad biológica con la que se manifiestan, estamos atrapados por los sentimientos como cuando decimos que el deseo o la rabia o el amor nos enloquece o el miedo nos hace retroceder o nos paraliza ante un peligro percibido como inminente. En esos casos, decimos que estamos atrapados por los sentimientos, y nos cuesta afirmar que los sentimientos son nuestros, como algo que nos pertenece, puesto que no tenemos dominio sobre ellos. Los neurólogos y otros profesionales ${ }^{8}$ intentan aclarar ese lado oscuro de nuestras reacciones más intensas que parecen escapar a todo control de lo que se considera la parte más evolucionada de nuestro cerebro.

Sin embargo, la mayoría de las veces, los sentimientos no escapan a nuestro dominio. Son experiencias conscientes en las que nos encontramos implicados e interesados; experiencias sentidas como perjudiciales o beneficiosas. Lo importante de los sentimientos es la evaluación afectiva de las realidades en cuanto que nos afectan como gratificantes o perjudiciales. Lo que distingue a ciertas sensaciones como sentimientos es la comprensión subyacente de una situación, en la que hay un juicio implícito dentro de la sensación misma y la experiencia continuada de tal sensación. Tener los sentimientos de alegría o tristeza, por ejemplo, consiste en sentirme alegre por estar con un amigo o triste por la pérdida del mismo; tales sentimientos consisten en tener tanto las sensaciones como los juicios evaluativos que las acompañan.

Como los sentimientos son estados del sujeto en los que hay presente una evaluación afectiva, una valoración de las realidades como perjudiciales o favorables para su vivir, a través de ellos cada sujeto manifiesta un modo de comprender y definir su posición frente a las personas o las situaciones con las que se relaciona. Los sentimientos, en cuanto muestran significado y juicio, están abiertos al cambio a través de la reflexión y de la deliberación sobre los elementos que componen las situaciones complejas en las que se vive; y también a través del análisis crítico de los valores implicados en los procesos de evaluación de tales situaciones de vida. Los sentimientos son más que sensaciones: "Son evaluaciones, y como tales pueden ser "educadas". Aquí podemos ver el puente tantas veces derribado, entre el

8. Joaquín García Carrasco $(2005,17)$, ante la pregunta de ¿cómo se forman los sentimientos? dice: "Esta pregunta resume todo el mapa de trabajo para la elaboración de una pedagogía de la sensibilidad. A un programa tan vasto debiera corresponder una epistemología compleja". Y enumera: una epistemología genética, una epistemología psicobiológica, una epistemología evolutiva y una epistemología sociocultural. Ante la magnitud de tal empresa, manifestamos que nuestro trabajo se limita a la presentación de algunos pensamientos de autores que nos parecen de importancia en la educación moral. 
sentimiento y la inteligencia, entre la acción, frecuentemente impelida por la emoción, y el juicio, demasiadas veces desconectado del sentimiento" (Pring, 2005, 153).

La posibilidad de la educación de los sentimientos, la educabilidad de los sentimientos, radica en su dimensión de evaluación afectiva respecto a las realidades que afectan al sujeto. Tiene el mismo fundamento que la educabilidad de las actitudes, como no puede ser de otra manera, puesto que: "El componente afectivo (de las actitudes) se refiere a los sentimientos o evaluación de la persona sobre algún objeto, persona, resultado o suceso" (Escámez y Ortega, 1986, 37). Nadie, medianamente riguroso en el campo del conocimiento pedagógico, discute la posibilidad de cambiar actitudes indeseables ni de generar actitudes positivas hacia la convivencia; sin embargo, no sucede lo mismo con los sentimientos. Es hora de plantearse seriamente la falacia de la inmutabilidad de los sentimientos. Consiste tal falacia en valorar los sentimientos como algo que nos ocurre y escapa totalmente a nuestro control. Como hemos dicho anteriormente, a veces tenemos sentimientos que nos llevan a perder el control de nosotros mismos y nos llevan a situaciones no deseadas; y, con frecuencia, experimentamos la dificultad de controlar nuestros miedos y odios. Tales experiencias y dificultades, sin embargo, no pueden llevar a la conclusión errónea de que los sentimientos no pueden ser desarrollados, encauzados o modificados por la educación (García Moriyón, 2005; Goleman, 2004).

La deliberación, la reflexión y el análisis crítico de las situaciones sociales, y de los valores implicados en las mismas, pueden ser procedimientos pedagógicos para el cambio o transformación de los sentimientos. A través de técnicas de cooperación y de comunicación persuasiva, entre otras, podemos intentar erradicar convicciones que sostienen sentimientos y conductas inadecuadas. Los estudiantes, y todas las personas, estamos impregnados de creencias asumidas inconscientemente y de creencias aceptadas por la presión social que generan sentimientos inmorales. Los esfuerzos por poner entre paréntesis tales creencias, someterlas a la razón y, si es necesario, sustituirlas por otras más acordes con una vida moral, es una tarea preferente de la educación.

Retomemos la pregunta que habíamos formulado anteriormente: ¿Por qué todas las teorías morales se han planteado la educación de los sentimientos? La verdad es que, en la mayoría de las tradiciones morales, se habla de la educación de los sentimientos como parte de la educación moral del individuo. Y ello por dos razones principales: la primera razón porque hay sentimientos malos y sentimientos buenos, aunque, en la mayoría de ellos, la cualificación de bondad o maldad depende del uso que se haga de los mismos; y, la segunda razón, por la importancia que tienen para dinamizar o aletargar el comportamiento moral.

De acuerdo con J. A. Marina (1996), hay tres criterios para evaluar moralmente los sentimientos como buenos o malos. El primer criterio es considerar malos los sentimientos que anulan la libertad y buenos aquellos que promocionan la misma. El segundo de los criterios es considerar malos los sentimientos que incitan a conductas perturbadoras de la convivencia y buenos los sentimientos que la facilitan. Y el tercer criterio es la adecuación o inadecuación de los sentimientos respecto de 
un valor presente; por ejemplo, la indignación ante una situación injusta es un sentimiento adecuado o la desvergüenza que tienen quienes abusan del poder es un sentimiento inadecuado.

Aunque bien es verdad que la mayoría de los sentimientos, como decía Aristóteles, no son buenos ni malos, dependiendo su cualificación moral del ordenamiento que hagamos de los mismos hacia la virtud o hacia el vicio. Esa indeterminación moral de los sentimientos hace de ellos objeto de educación moral. La evolución no ha programado a la mente humana para que actúe conforme a comportamientos típicos de la especie, porque no hay comportamientos típicos de la especie en sentimientos como la venganza o la reciprocidad. Es probable que ninguna conducta humana carezca de fundamento genético en términos absolutos, pero lo seguro es que ningún sentimiento humano está programado genéticamente de un modo inequívoco. Como ha puesto de manifiesto F. Savater (2003, 175), la pregunta clave es quién somos o quién queremos ser:

\begin{abstract}
A mi juicio, elegir hoy la humanidad es optar por un proyecto de autolimitación en lo tocante a cuanto podemos hacer, de simpatía solidaria ante el sufrimiento de los semejantes y de respeto ante la dimensión inmanejable que lo humano debe conservar para el humano. Autolimitación, solidaridad, respeto: saberse humano no es aceptar un hecho, biológico o cultural, sino tomar una decisión y emprender un camino.
\end{abstract}

Además, la educación moral de los sentimientos, en todas las épocas, se ha considerado como fundamental para que las personas tengan el vigor y la fuerza necesaria, que los sentimientos aportan a las acciones, para que sean o alcancen aquello que han proyectado ser o alcanzar en sus vidas. Y es que los sentimientos han tenido que ser reconocidos como el apoyo más importante de la vida moral, ya que refuerzan las ideas y principios morales y, a veces, pueden más que éstos. La importancia de la educación de los sentimientos radica en el poder de que son capaces, en la movilización de energías que no siempre lleva consigo el querer de la voluntad, y que sólo surgen cuando comprometemos también nuestro corazón.

La clave importante radica (Ibáñez-Martín, 2005, 16), en que el sentimiento no es sólo una simple respuesta ante un determinado hecho, ni se traduce sólo en la realización de iniciativas concretas, que a veces exigen mucho esfuerzo, sino lo más importante del sentimiento es que puede acarrear un compromiso de la totalidad del propio ser, con la decisión de poner todos los medios que sean precisos en orden a alcanzar lo que se ha establecido como deber: "De ahí la importancia de esforzarse por educar los sentimientos, por saberles atribuir exactamente el importante papel que tienen en la existencia humana".

¿Cuáles son los sentimientos morales a los que hay que prestar especial atención en la educación moral? Con el riesgo de equivocación que supone optar por el desarrollo preferencial de unos sentimientos frente a otros, el análisis efectuado a lo largo de este trabajo nos conduce a considerar, como preferentes en la educación, a los sentimientos morales siguientes: la pasión por la justicia o la justicia 
como felicidad, la solidaridad, la responsabilidad, la compasión y el amor. Algunos de ellos, como la compasión y la responsabilidad, han sido analizados a través de pensadores tan importantes como Adorno, Horkheimer y Levinas. A continuación, haremos un breve análisis de la justicia como felicidad, la solidaridad y el amor.

Un sentimiento moral, que es fundamental desarrollar en la educación, es el interés o pasión por la justicia como un componente de la felicidad. En la historia de las tradiciones éticas, o filosofía morales, se han venido enfrentando aquellas que aspiran a conducir a las personas a la felicidad con aquellas que consideran que lo verdaderamente moral es actuar por respeto a la ley de la conciencia; así ha habido y perviven dos grandes concepciones de la moralidad: las morales de la vida buena y las morales deontológicas ${ }^{9}$. La aspiración a la felicidad y la aspiración a la justicia se han venido presentado como dos aspiraciones morales incompatibles. Sin embargo, consideramos que el camino más efectivo para un comportamiento moral es la unión de felicidad y justicia, en concreto, la consideración de la justicia como un componente de la felicidad.

Si por justicia entendemos la puesta en marcha de los mecanismos de universalidad y reciprocidad, ningún ser humano maduro puede sentirse mínimamente satisfecho en una sociedad en la que otros seres humanos son víctimas de discriminaciones o maltratos. Lo que pretendemos decir, usando terminología y conceptos de la Teoría del Desarrollo del Juicio Moral de Piaget y Kohlberg, es lo siguiente: el sujeto va desplegando sus capacidades de juicio moral y, al unísono, ampliando su ámbito de intereses, es decir, que mientras que en el nivel preconvencional las satisfacciones se producen prácticamente en solitario, a nivel convencional la satisfacción se deriva de la participación activa en el grupo social, así como de una serie de contraprestaciones y servicios mutuos entre los diversos miembros del grupo. Por último, en el nivel postconvencional, el sujeto deriva sus satisfacciones de dos fuentes: la conformidad consigo mismo y la conformidad de sus acciones con principios morales universales. En otros términos, la felicidad en sus niveles avanzados tiene presente el componente de la justicia que se manifiesta en tendencias a la reciprocidad, a la simpatía y a la asunción de los intereses de los demás como intereses propios.

9. Las morales de la vida buena entienden que la moralidad de las acciones se mide por la felicidad que pueden proporcionar. Estas morales son teleológicas, puesto que no consideran que haya acciones buenas o malas en sí, sino que su bondad o maldad se dice por referencia a un fin: la felicidad. Si bien la felicidad es entendida de modo distinto en cada una de las tradiciones morales de la vida buena; desde identificarla con el placer hasta concebirla como la actividad más perfecta, según la virtud más excelente; desde entenderla como felicidad individual a entenderla como felicidad social. Por el contrario, las éticas deontológicas consideran que la felicidad es una meta de la persona en la que no se distingue de los demás seres naturales; y si la persona tiene dignidad y no precio es porque es capaz de sustraerse al orden natural, capaz de dictar sus propias leyes, en definitiva, que la persona es autolegisladora y autónoma. Las éticas deontológicas son aquellas que consideran que el ámbito moral es el de la realización de la propia autonomía. El deontologismo destaca que ni la felicidad individual ni la felicidad colectiva pueden anteponerse al respeto o promoción de lo valioso en sí: la persona humana. 
La tesis que defendemos es que la justicia y la felicidad son inseparables si pretendemos que los estudiantes sean educados para un comportamiento moral en las situaciones sociales en las que les toca vivir, a veces difíciles; no encontrarán la fuerza y los ánimos para comprometerse en causas justas, en comprometerse por la justicia, si no encuentran felicidad, o satisfacción, en su compromiso. Todos sabemos la dificultad de caracterizar a la felicidad (Altarejos, 1983), puesto que es un asunto individual. Pero, de una u otra manera, se tiene ese sentimiento cuando hay la percepción de haber desarrollado las capacidades personales, haber satisfecho los intereses propios y, sobre todo, se tiene un buen concepto de sí mismo. Sin embargo, desde la perspectiva moral, la felicidad no puede ser recluida en el ámbito de lo privado. Es también un asunto público: la República de Platón es tanto un tratado de la felicidad a nivel individual como colectivo.

Por ello, la educación moral de nuestro tiempo tiene que encontrar la fórmula que haga posible que los estudiantes compartan unos mínimos de justicia para todos, progresivamente ampliables, y se comprometan apasionadamente por ellos, desde los máximos de felicidad y de sentido de la vida que cada uno de los individuos y grupos tienen; que, a veces, pueden compartir con otros $y$, otras veces, pueden no compartir. Con una visión así, se puede superar la separación inadecuada entre la justicia, como cosa de la comunidad política, y la felicidad, como algo perteneciente al ámbito de lo privado (Cortina, 2001).

El segundo de los sentimientos morales que hay que promocionar preferentemente en la educación es el sentimiento de solidaridad. La solidaridad, tal como es entendida en la Modernidad, surge cuando la comunidad política necesita legitimarse por sí misma a través del Estado y no puede apelar a la fraternidad, puesto que los miembros de la comunidad ya no comparten las mismas creencias filosóficas o religiosas. El vínculo social, que en épocas anteriores nacía de una fraternidad, fundada en un origen común, había perdido parte de la fuerza que tenía y la solidaridad se convierte en una cuestión de simpatía y afecto compartido, de amistad cívica libremente elegida.

La solidaridad actualmente se plantea desde una cultura de la colaboración deseable. En nuestros días, la solidaridad se manifiesta en la atención y el cuidado de las otras personas o grupos, especialmente los excluidos y marginados, compartiendo sus intereses y necesidades, compartiendo su dolor y su sufrimiento. La solidaridad adquiere su auténtica dimensión como sentimiento moral, cuando percibimos que todas las personas del planeta Tierra somos interdependientes. Esto significa que la humanidad en su conjunto tiene que ser percibida como un sistema interdependiente de relaciones económicas, culturales, políticas y religiosas. Dicho con otras palabras, la interdependencia tiene que ser asumida como una realidad objetiva que nos demanda imperativamente las correspondientes respuestas para asegurar nuestra supervivencia y la supervivencia de la humanidad.

Desde la anterior perspectiva, la solidaridad ha sido caracterizada como un sentimiento que tiene mucho que ver con la compasión por la que aceptamos compartir los sentimientos de los otros, nacido de la conciencia de una interdependencia 
entre ellos y nosotros, entre su situación y la nuestra. La solidaridad tiene mucho que ver con la gratuidad, pero no es sólo gratuidad porque la preocupación por el otro es inseparable de una preocupación por mí, se trata de una preocupación por nosotros y por nuestra situación.

La solidaridad no es simplemente un sentimiento, también es percibida como el valor más característico de nuestro tiempo, y como un modo de ser; se trata de un elemento estructural de la vida moral y tiene que adquirirse en todos los aspectos (cognitivo, afectivo y conductual) de la personalidad moral. La solidaridad es una virtud que engarza la vida privada con la vida pública y la moral personal con la moral social. I. Carreras y M. Osés (2002) describen la solidaridad así: se trata de tomar conciencia de que mi vida, mis decisiones están conectadas con las de miles de personas y entender cuáles son esos mecanismos de conexión; además ponerse en el lugar de quienes están en desventaja y pasar a la acción para modificar, en la medida de lo posible, esa situación.

En la historia de la ética, el amor ha sido el primero y más importante de los sentimientos; podemos decir que es un sentimiento moral de primer orden que ha de ser cultivado en la educación. La génesis de la moral individual tiene sus raíces en el amor y la moral no es sino el desarrollo, en un sentido muy concreto, de aquel amor inicial ${ }^{10}$. El amor de los padres, de los hermanos y de los cercanos es el primer alimento con el que se nutre el niño antes de introducirse autónomamente en la vida de los demás. Los cuidados de los padres y demás parientes no constan sólo de caricias, de besos, y de un sinfín de palabras con las que expresan su amor. En el momento que el niño empieza a dar sus primeros pasos en dirección a una reciprocidad más amplia, ese mismo amor, sin dejar de ser expresivo, comienza a impartir información, a señalar imperativos, a hacer que el niño se mueva distinguiendo lo que es bueno de lo que no es bueno. De esta manera es como el niño empieza a ir dando forma a todos sus sentimientos morales. Una persona que carece de los afectos propios del amor (y que lo componen la ternura, el cariño, la atención, la preocupación por el otro, el gozo de estar juntos, la expresión del sentimiento a través de gestos, palabras, regalos e incluso sorpresas), tiene difícil empezar a andar por la vía de la moral. Amor y moral nacen juntos, casi gemelos.

¿En qué se separa el amor y la moral inicial para dar lugar al amor pasión y a la moral en cuanto tal? En el amor del enamorado, del apasionado, del que reduce a un punto todo el espacio y el tiempo, la fuerza amorosa se concentra en la persona amada. Y en esa concentración queda atrapado el amante; actúa casi por necesidad. De ahí que crea que todo el bien se encierra en esa persona; en ella, encuentra toda la fuente de placer, si es correspondido, y toda la fuente de sufrimiento, si no es correspondido.

10. En este punto, seguimos las tesis centrales expuestas en la conferencia pronunciada por Javier SÁBADA en la sede en Valencia de la UIMP, julio de 2002, con el título El amor contra la moral. Documento policopiado. 
La moral introduce racionalidad en medio de los sentimientos. Por mucho que éstos sean un ingrediente de la moral, la razón trata de encauzarlos, ordenarlos, jerarquizarlos. La Regla de Oro de la moral, "no hagas a los demás lo que no quieras que te hagan", se encuentra en la tradición cristiana (Mateo, 7,12 ) y en otras culturas, respondiendo probablemente a un sentimiento de solidaridad universal. Pero ha sido la razón, a través de los siglos, la que ha ido edificando siquiera los cimientos de una moral universal. Podemos decir que el sentimiento del amor, como sustrato más profundo, tiene, entre otras, dos ramificaciones de importancia. Una es el amor pasión, con su intensidad y focalización en una persona; y la otra, la moral, con su capacidad de universalizar y ver a la humanidad como un todo.

El amor pasión y la moral son dos cosas distintas, aunque con un origen común. ¿Puede ayudar el amor a la moral y la moral al amor? J. Sábada (2002) cree que sí. El amor ayuda al nacimiento de la moral, y la seguirá ayudando si después acompaña a nuestras acciones a modo de sombra para que no se deslicen hacia la rigidez de una justicia sin gracia. La moral tiene que ser una ayuda para el amor, por ejemplo para no hacer mal a nadie; todos sabemos por experiencia la dificultad de no hacer daño al amigo que traiciona la confianza que hemos depositado en él.

Pero, el sentimiento del amor no sólo tiene la vertiente de la pasión. J. Xirau ha mostrado, en Amor y mundo (1940), otras vertientes del sentimiento del amor y el papel central que tiene para la educación, en general, y para la educación moral.

Se supone que el educando tiene el derecho a realizar su propio desarrollo. La condición básica de toda educación consiste en dejar vivir al educando. Sin embargo, Xirau piensa que dejar vivir no es una actividad específicamente educadora. No es vida, una vida que consiste sólo en ir viviendo. Un tal género de vida para la persona es aquello que más se le parece a la muerte. La vida de la persona es siempre vivir para alguna cosa que le reclama. Educar no puede ser simplemente dejar vivir, sino vivificar, hacer vivir: proporcionar las condiciones y los medios indispensables para que sea posible una vida humanamente rica. La educación tiene como objetivo llevar a plena actualidad las posibilidades o virtualidades que hay en el educando, conducir su vida a la plenitud. Es preciso que el educando viva; pero es indispensable, además, que viva bien.

Xirau se pregunta, ¿en qué consiste la vida buena? Puesto que no hay una vida buena para todos. Bueno es lo bueno para cada cual. El mundo se halla impregnado de cosas valiosas, de posibilidades que reclaman a cada persona. Del choque de las fuerzas e impulsos en conflicto es preciso que surja la silueta de una acción precisa: conquistar todos los días la libertad y la vida, puesto que el hombre es el único ser capaz también de perdición. La educación es una empresa para que cada uno busque ganarse la vida personal auténtica; la función de la educación no es otra que promover, orientar y fomentar la vida de cada cual hacia el cumplimiento de su propio proyecto de lo que quiere ser y hacer. A esto se llama "la vocación de cada uno"; hallar la vocación personal es hallar la libertad. Así se concreta el deber ser 
abstracto en un imperativo personal. Es preciso que cada uno sea lo que es con toda verdad y fidelidad.

De ahí que la educación tenga que ejercerse en un contexto de comprensión, respeto y profunda tolerancia. Toda persona tiene derecho a trazar el proyecto de su existencia. Sólo siendo en verdad uno mismo es posible ponerse al servicio de los demás y de las causas justas. La función del educador consiste en ayudar a cada uno de los discípulos a descubrir el propio camino. Es una función delicada y difícil.

Ahí es donde la educación y el amor muestran toda su imbricación. No es posible la educación sin amor. La sola presencia de la actitud amorosa descubre y alimenta en el educando una riqueza de valores antes insospechados y los hace gradualmente presentes en su vida. Educar consiste en descubrir con mirada delicada todas las aptitudes y capacidades del educando y hacerlas efectivas. Llevarlo al pleno desenvolvimiento del propio ser, hacer que sea con plenitud aquello que es. En tal cosa consiste la formación de la personalidad, la educación del carácter, el descubrimiento de las aptitudes y la satisfacción de los intereses.

\section{CONCLUSIONES}

Primera conclusión. Hemos conceptuado a los sentimientos como estados del sujeto en los que hay presente una evaluación, una valoración de las realidades como perjudiciales o favorables para su vivir. A través de ellos, cada sujeto manifiesta un modo de comprender y definir su posición frente a las personas o las situaciones con las que se relaciona. En cuanto los sentimientos muestran significado y juicio, tienen a la razón como un componente fundamental. Así mismo, los sentimientos guían las decisiones instante tras instante, trabajando mano a mano con la mente racional y capacitando o incapacitando al pensamiento mismo.

Segunda conclusión. En las tradiciones morales que se inician en la Ilustración, se produce un divorcio entre razón y sentimientos. Ello se debe al intento ilustrado, que se ha mantenido en la mayoría de las tradiciones de la filosofía moral, de determinar las condiciones que tiene que cumplir la razón para alcanzar un fundamento satisfactorio del hecho moral o establecer una explicación satisfactoria del origen del fenómeno moral. No preocupaba a los ilustrados, como propósito primero, fundamentar las normas que guían las acciones de las personas para ser virtuosas y felices, tal como hasta entonces habían pretendido las tradiciones de la filosofía moral desde los griegos. Dicho de otra manera: la investigación sobre lo que las personas deben hacer para ser buenas personas y buenos ciudadanos ha sido sustituida por la investigación sobre las condiciones por las que se puede adquirir el conocimiento moral. Las teorías morales dejan paso a las metateorías morales. Tales planteamientos de la filosofía moral ilustrada han tenido un fuerte impacto en teorías de la educación moral como la Teoría del Desarrollo del Juicio Moral y la Filosofía para Niños, que han valorado menos el cultivo moral de los sentimientos. 
Probablemente esa influencia se haya producido también en otras teorías pedagógicas, pero nuestro estudio es limitado y no permite una conclusión tan general.

Tercera conclusión. La educación moral tiene que dirigirse a la razón y a los sentimientos, además de a la acción de los estudiantes. Nuestro trabajo es una apuesta a favor de hablar de sentimientos morales y de educación de los mismos. El presente artículo debiera concluir que promover la educación de los ciudadanos sin prestar atención a sus sentimientos morales, o al modo como se forman, es un error pedagógico.

\section{BiBLIOGRAFÍA}

AdORno, Th. W. (1975) Dialéctica negativa. Madrid, Taurus.

- (2004) Minima Moralia. Madrid, Akal.

Altarejos, F. (1983) Educación y felicidad. Pamplona, EUNSA.

ARISTÓTELES (1991) Obras. Madrid, Aguilar.

ARTETA, A. (1996) La compasión. Barcelona, Paidós.

Bernal, A. (1998) Educación del carácter/educación moral. Propuestas de Aristóteles y Rousseau. Pamplona, EUNSA.

BRANDT, R. B. (1978) A theory of the good and the right. Oxford, Oxford University Press.

- (1982) Teoría ética. Madrid, Alianza.

CARreras, I. y Oses, M. (2002) Vivir solidariamente es posible dia a dia. Barcelona, Planeta.

CHALIER, C. (2002) Por una moral más allá del saber. Kant y Levinas. Madrid, Caparrós.

Cortina, A. (2001) Alianza y contrato. Politica, ética y religión. Madrid, Trotta.

EsCÁmez, J. (2003) Pensar y hacer hoy educación moral, Teoría de la Educación, 15, 21-31.

EsCÁmeZ, J.; GARCíA, R. y PÉrez, C. (2003) La educación moral ante el reto de la pobreza, Teoría de la Educación, 15, 185-212.

EsCÁMEZ, J. y ORTEGA, P. (1986) La enseñanza de actitudes y valores. Valencia, Nau llibres.

Etzioni, E. (1988) The moral dimension. New York, Free Press.

García Carrasco, J. (2005) ¿Cómo se forman los sentimientos?, en Varios. Actas V Congreso Internacional de Filosofía de la Educación. Madrid, Dykinson, 17-26.

García Moriyón, F. (2005) La educación de los sentimientos, en Varios. Actas V Congreso Internacional de Filosofia de la Educación. Madrid, Dykinson, 323-331.

Goleman, D. (1996) Inteligencia emocional. Barcelona, Kairós.

- (2004) La práctica de la inteligencia emocional. Barcelona, Kairós.

GUISÁN, E. (1986) Razón y pasión en ética. Los dilemas de la ética contemporánea. Barcelona, Anthropos.

HARE, R. M. (1952) Freedom and reason. Oxford, Oxford University Press.

- (1981) Moral thinking. Oxford, Oxford University Press.

Hoffman, M. L. (2002) Desarrollo moral y empatía. Barcelona, Idea Books.

HoRKHeIMER, M. (1999) Materialismo, metafisica y moral. Madrid, Tecnos.

- (2000) Anbelo de justicia. Madrid, Trotta.

- (2002) Crítica de la razón instrumental. Madrid, Trotta.

Horkheimer, M. y Adorno, Th. W. (1994) Dialéctica de la Ilustración. Madrid, Trotta.

Hume, D. (1977) Tratado de la naturaleza humana. Madrid, Editora Nacional, t. 2, ed. de F. Duque. 
IbÁÑEZ-MARTín, J. A. (2005) Sentimientos y razones en la educación cívica, en VARIOS. Cultivar los sentimientos. Propuestas desde la Filosofía de la Educación. Madrid, Dykinson, 13-30.

JAEGER, W. (1962) Paideia. Los ideales de la cultura griega. México, FCE.

Kant, E. (1973) Observaciones sobre el sentimiento de lo bello y lo sublime. México, Porrúa.

- (2004) Crítica de la razón práctica. Madrid, Alianza.

- (2005) Fundamentación para una metafísica de las costumbres. Madrid, Alianza.

LEVI, P. (1989) Los bundidos y los salvados. Barcelona, Muchnik.

LEVINAS, E. (1987) Totalidad e Infinito. Ensayo sobre la exterioridad. Salamanca, Sígueme.

- (1991) Etica e Infinito. Madrid, Visor.

- (1993a) Humanismo del Otro Hombre. Madrid, Caparrós.

- (1993b) Entre nosotros. Valencia, Pre-textos.

Lickona, T. (1991) Educating for character. How our schools can teach respect and responsibility. New York, Bantam Books.

MacinTYRE, A. (1987) Tras la virtud. Barcelona, Crítica.

- (1994) Justicia y racionalidad. Barcelona, EIUNSA.

Mardones, J. M. ${ }^{a}$ (2005) Religión y democracia. (Texto policopiado).

MARÍAS, J. (1992) La educación sentimental. Madrid, Alianza.

MARINA, J. A. (1996) El laberinto sentimental. Barcelona, Anagrama.

ORTEGA, P. (2004) La educación moral como pedagogía de la alteridad, Revista Española de Pedagogía, 227, 5-30.

ORTEga, P. y Mínguez, R. (2001) La educación moral del ciudadano de boy. Barcelona, Paidós.

Platón (1966) Obras completas. Madrid, Aguilar.

PrING, R. (2005) El arte y la finalidad moral de la educación, en VARIOs. Cultivar los sentimientos. Propuestas desde la Filosofía de la Educación. Madrid, Dykinson, 149-164.

SÁBADA, J. (2002) El amor contra la moral. (Texto policopiado).

SAVATER, F. (2003) El valor de elegir. Barcelona, Ariel.

SEOANE, J. (2004) Del sentido moral a la moral sentimental. El origen sentimental de la identidad y ciudadanía democrática. Madrid, Siglo XXI.

Steinberg, P. (2004) Crónicas del mundo oscuro. Barcelona, Círculo de Lectores.

TAFAlLA, M. (2003b) Recordar para no repetir: el nuevo imperativo categórico de Th. W. Adorno, en MARdones, J. M. y MATE, R. (eds.). Etica ante las víctimas. Barcelona, Anthropos, 126-155.

Wittgenstein, L. (1989) Conferencia sobre ética. Barcelona, Paidós.

XIRAU, J. (1998-2000) Obras completas. Barcelona, Anthropos-Caja Madrid.

Zamora, J. A. (2004) Th. W. Adorno. Pensar contra la barbarie. Madrid, Trotta.

ZuBIRI, X. (1980) Inteligencia sentiente. Madrid, Alianza-Sociedad de Estudios y Publicaciones.

- (1986) Sobre el hombre. Madrid, Alianza-Sociedad de Estudios y Publicaciones.

- (1992) Sobre el sentimiento y la volición. Madrid, Alianza-Sociedad de Estudios y Publicaciones. 